Int J Infect Microbiol 2013;2(1):3-6

\section{Immune status in infection by cytomegalovirus in women with bad obstetric history}

\author{
Acharya D, ${ }^{*}$ Shrestha S, Bogati B, Sherchan \\ JB, Karki P, Yadav A, Madhup SK, Tuladhar \\ NR
}

\section{School of Medical Science, Kathmandu University, Dhulikhel, Kavre, Nepal}

\footnotetext{
*Correspondence to: Mr. Dhruba Acharya, Department of Microbiology, Kathmandu University School of Medical Sciences, Kathmandu University, Dhulikhel, Kavre, Nepal, email: dhruba099@gmail.com, Tel. No.: (+977)-9841456286.
}

\begin{abstract}
INTRODUCTION: Viral infections during pregnancy carry a risk for intrauterine transmission which may result in fetal damage. Bad obstetric history implies for previous unfavorable foetal outcome in terms of two or more consecutive spontaneous abortions, history of intrauterine foetal death, intrauterine growth retardation, still birth, early neonatal death and congenital anomalies. Cytomegalovirus, a ubiquitous virus belonging to the herpes family, is known to cause abnormal fetal outcome. We aim to determine the possible involvement of CMV infection among pregnant women with bad obstetric history
\end{abstract}

MATERIALS AND METHODS: A cross sectional study was carried out among 136 women with bad obstetric outcome attending Dhulikhel HospitalKathmandu University Hospital. The cytomegalovirus specific IgG and IgM antibodies were determined by ELISA test. Data were analyzed using SPSS, version 17.0 and interpreted according to frequency distribution and percentage. The data was considered significant if the $\mathrm{p}$-value was $<0.05$.

RESULTS: The results revealed that 87 (63.9\%) out of 136 patients were positive for CMV IgG antibodies and only one $(0.007 \%)$ patient was positive for CMV IgM. The majority of the patients were of the age between 20 and 29 years (99/136) and it was observed that most of the positive CMV IgG were participants of the same age group (63/ 99). There was no significant association of CMV seropositivity with the age of participants ( $p$ value 0.9 ).

CONCLUSION: CMV infection could be the risk factor for $\mathrm{BOH}$ and may play a vital role in determining the foetal outcome. Thus we recommend routine serological testing to all pregnant women with or without $\mathrm{BOH}$ attending the antenatal clinics for both CMV specific IgG and IgM.

KEY WORDS: Seropositivity, Foetal outcome, Risk factor, Pregnancy, Antinatal

Article submitted 20 October. Reviewed 28 November. Author correction 15 December. Final version accepted 30 January 2013. 


\section{INTRODUCTION}

Bad obstetric history (BOH) implies for previous unfavorable foetal outcome in terms of two or more consecutive spontaneous abortions, history of intrauterine foetal death, intrauterine growth retardation, still birth, early neonatal death and congenital anomalies. There might be different causes of BOH like genetic, hormonal, abnormal maternal immune response and maternal infection. ${ }^{1}$ Primary infections caused by the TORCH complex (also known as STORCH, TORCHES or the TORCH infections)-Toxoplasma gondii, rubella virus, cytomegalovirus (CMV) and herpes simplex virus (HSV) are the major causes of BOH. They are a group of viral, bacterial, and protozoan infections that gain access to the fetal bloodstream transplacentally via the chorionic villi. ${ }^{2}$

CMV is the most frequent cause of congenital infection in humans. About 10 to 20 percent of infected infants may suffer sensorineural hearing loss, ocular damage or impairment of cognitive and motor function. ${ }^{3}$ The common modes of infection of this DNA virus are through saliva (kissing), urine, stool, breast milk and unscreened blood tramsmission. For most healthy people who acquire CMV infection after birth or through blood transfusion, there are few symptoms and no long term sequelae. Therefore for the vast majority of individuals, CMV infection is innocuous. However, foetal damage is more likely to be severe when maternal infection occurs early in pregnancy because of their immunocompromised state and risk of infection to the fetus whose immune system is not fully developed. ${ }^{2,4}$ Not all maternal infections result in fetal transmission and damage. Only 35 to $50 \%$ of maternal primary infections and $0.2-2 \%$ of the secondary infections lead to fetal infection, out of which only $5-15 \%$ in primary infection and about $1 \%$ in secondary infections are clinically affected. ${ }^{5}$

The seroprevalence of CMV among women of childbearing age ranges from $30 \%$ to $90 \%$ in different countries especially in developing countries with lower socioeconomic conditions. ${ }^{4}$ Since the prevalence of congenital infection varies with the prevalence of infection in population, the need to determine the seroprevalence of CMV antibody in pregnant women cannot be overemphasized. Irrespective of the number of babies affected, CMV embryopathy (sensoryneural hearing loss, choreoretinitis, mental retardation and fetal death) should be a major concern for public health. Screening of pregnant mother is necessary to avoid the transmission of CMV. Hence we aim to determine the possible involvement of CMV infection by measuring seroprevalence of this viral infection among pregnant women with $\mathrm{BOH}$.

\section{MATERIALS AND METHODS}

A cross-sectional study was carried out at the antenatal clinic of Dhulikhel Hospital- Katmandu University Hospital, Kavre, Nepal. 136 women with BOH were recruited for the study between January 2011 and February 2012. Participants with no history of BOH were excluded. Serum samples from the participants were tested for IgG and IgM against CMV using the ELISA test by Commercial Diagnostic Automation- USA following manufacturer's instructions. The cut-off of IgG and IgM were set at 1.0 by kits manufacturer. Samples with concentration above cutoff were considered positive and below cutoff were considered negative for CMV antibody detection. The controls and calibrators were used to validate the procedure recommended by manufacturer of the kit. Data were analyzed using SPSS, version 17.0 and interpreted according to frequency distribution and percentage. Data were presented in tables. The Pearson's chi square test was applied to detect the association of risk factors. The data was considered significant if the $\mathrm{p}$-value was $<0.05$.

\section{RESULTS}

A total of 136 women with BOH were enrolled and screened for the presence of anti-CMV IgG and IgM antibodies. The seroprevalence of CMV-IgG and CMV-IgM are shown in Table 1. The results revealed that $87(63.9 \%)$ out of 136 participants were positive for CMV IgG antibodies and only one (0.1\%) participant was positive for CMV IgM. The majority of the participants were of the age between 20 and 29 years $(99 / 136)$ and it was observed that most of the positive CMV IgG were patients of the same age group (63/99) as shown in Table 2. The only women who was IgM positive against CMV was of 23 years old. No association of age as a risk factor of CMV seropositivity was noted ( $\mathrm{p}$ value 0.9 ).

Table 1. Prevalence of CMV-IgG and CMV-IgM

\begin{tabular}{lcccc}
\hline \multirow{2}{*}{ Result } & \multicolumn{2}{c}{$\begin{array}{c}\text { Prevalence of } \\
\text { CMV-IgG }\end{array}$} & \multicolumn{2}{c}{$\begin{array}{c}\text { Prevalence of } \\
\text { CMV- IgM }\end{array}$} \\
\cline { 2 - 5 } & $\mathrm{n}$ & $\%$ & $\mathrm{n}$ & $\%$ \\
\hline Positive & 87 & 63.9 & 1 & 0.1 \\
Negative & 49 & 36.1 & 135 & 99.9 \\
Total & 136 & 100.0 & 136 & 100.0 \\
\hline
\end{tabular}

\section{DISCUSSION}

Infection acquired in utero is a significant cause of 
Table 2. Prevalence of CMV-IgG and CMV-IgM in different age groups

\begin{tabular}{lccccc}
\hline \multirow{2}{*}{ Age } & Total & \multicolumn{2}{c}{$\begin{array}{c}\text { CMV-IgG } \\
\text { Positive }\end{array}$} & \multicolumn{2}{c}{$\begin{array}{c}\text { CMV- IgM } \\
\text { Positive }\end{array}$} \\
\cline { 2 - 6 } & & $\mathrm{n}$ & $\%$ & $\mathrm{n}$ & $\%$ \\
\hline$<20$ & 19 & 12 & 63 & 0 & 0 \\
$20-29$ & 99 & 63 & 63 & 1 & 0.1 \\
$30-39$ & 15 & 11 & 73 & 0 & 0 \\
$\geq 40$ & 3 & 1 & 33 & 0 & 0 \\
Total & 136 & 87 & 63.9 & 1 & 0.1 \\
\hline
\end{tabular}

p value was 0.9

fetal and neonatal mortality and an important contributor to early and later childhood morbidity. ${ }^{6}$ It is evident that maternal infections play a critical role in pregnancy wastage and their occurrence in patients with $\mathrm{BOH}$ is a significant factor. Primary CMV infection during pregnancy carries a high risk of the intrauterine transmission which may result in severe fetal damage, including growth retardation, jaundice, hepatospleenomegaly and CNS abnormalities. Pre-conceptional primary infection carries a high risk identical to the risk of infection during early gestational weeks. ${ }^{7}$ Despite the fact of the association of $\mathrm{CMV}$ infection with $\mathrm{BOH}$, the epidemiology of CMV infection in general, pregnant or women with $\mathrm{BOH}$ have been poorly studied in Nepal. However, a pilot study done in Eastern Nepal has suggested that the previous history of pregnancy wastage and the serological evaluation of TORCH agents during current pregnancy must be considered while managing the cases of $\mathrm{BOH}^{1}$

The host defense against CMV infection in immunocompetent individuals combine cellular and humoral immune response which together prevent a severe CMV disease in the vast majority of infections. Antibodies of the IgM class are produced immediately after primary infection and may last for several months. IgM can be produced in the secondary infection in some cases. Antibodies of the IgG class are also produced immediately after infection and last for life. ${ }^{5}$ Our result revealed the occurrence of $63.9 \%$ IgG seropositive cases against CMV infection. This result shows majority of the women with $\mathrm{BOH}$ were past infected or immune to CMV infection. However it can not be concluded that $\mathrm{BOH}$ was the consequences of CMV infection in the past. No current infection was detected (IgM positive) in almost all cases except a single woman. This justify that there might not be any association between $\mathrm{CMV}$ seropositivity and $\mathrm{BOH}$ in these subjects.
A study from Maharasta, India has shown more than 90\% IgG seropositivity of CMV infection in women with $\mathrm{BOH}$ while another study from South India has shown seropositivity of below $25 \%^{2,8}$ So that varying number of seroprevalence has been recorded in different studies like our study (63\%). Only one IgM seropositive case in our study is not in accordance with another study done in Nepal Public Health Laboratory (NPHL) where around 15\% IgM seropositive cases were detected however that study was performed on the subjects of suspected TORCH infections and the study site is a referral center for diagnosis of infectious diseases. ${ }^{3}$ Decreasing trends of seropositivity of cytomegalovirus was observed in Japan where approximately $35 \%$ pregnant women are still infected with CMV. ${ }^{9}$ A national health and nutrition examination surveys from United State of America shows that many women of reproductive age are still at risk of primary CMV infection during pregnancy. ${ }^{10}$

It is noteworthy in this study that age of the patient is not associated with the risk of CMV positivity, because they did not reach significant level. It is for sure that the women of reproductive age group are at risk of gaining these infections irrespective of the specific age. In the present study seropositivity was observed more in the age group of 20 to 40 years which is similar to those found with the study done in Nigeria. ${ }^{4}$

Demonstration of CMV infection of the mother or fetus by laboratory testing has become an essential part of the assessment of pregnancies at risk. ${ }^{11}$ Although IgG and IgM of the samples were determined in our study, the actual interpretation is mainly based on the value of IgG, IgM and IgG avidity tests on paired sera. ${ }^{5}$ Therefore our increased number of CMV IgG positive cases only doesn't reflect the actual association of CMV infection with $\mathrm{BOH}$ of the patients.

\section{CONCLUSION}

The present study is directed at providing the profile of the seroprevalence of CMV infection among women with $\mathrm{BOH}$ attending Dhulikhel Hospital. The finding revealed the significant number of seropositivity of this infection. The maximum seropositivity was observed in the age group of (20-29) years. Nevertheless, it is well documented risk factor for $\mathrm{BOH}$ and may play a vital role in determining the foetal outcome. Thus we 
recommend routine serological testing to all pregnant women with or without $\mathrm{BOH}$ attending the antenatal clinics for both CMV specific IgG and IgM. An extensive study covering a large population should be conducted to know the seropositivity of CMV and also to know the real status of this infection in $\mathrm{BOH}$ cases.

\section{ACKNOWLEDGEMENTS}

We would like to acknowledge all the Laboratory Technicians of Department of Microbiology, Dhulikhel Hospital-Kathmandu University Hospital.

CONFLICT OF INTEREST: None to declare.

FINANCIAL INTEREST: None to declare.

\section{REFERENCES}

1. Kumari N, Morris N, Dutta R. Is screening of TORCH worthwhile in women with bad obstetric history: an observation from eastern Nepal. J Health Popul Nutr 2011;29:77-80.

2. Sadik MS, Fatima K, Jamil K, Patil C. Study of TORCH profile in patients with bad obstetric history. Biol Med 2012;4:95-101.

3. Lamichhane $S$, Malla $S$, Basnyat $S$, et al. Seroprevalence of IgM antibodies against the agents of torch infections among the patients visiting National Public Health Laboratory, Teku, Kathamndu. J Nep Health Res Council 2007;2:21-25.

4. Abduljaleel AA, Rabiu KA, Adewunmi AA, et al. Seroprevalence of cytomegalovirus antibodies amongst normal pregnant women in Nigeria. Int J Women Health 2011;3:423-428.

5. Mendelson E, Aboudy Y, Smetana Z, Tepperberg M, Grossman Z. Laboratory assessment and diagnosis of congenital viral infections: Rubella, cytomegalovirus, vericella zoster virus, herpes simplex virus, parvo B19 and human immunodeficiency virus. Reprod Toxicol 2006;21:350-382.

6. Binnicker MJ, Jespersen DJ, Harring JA. Multiplex detection of IgM and IgG class antibodies to Toxoplasma gondii, Rubella virus, and cytomegalovirus using a novel multiplex flow immunoassay. Clin Vaccine Immunol 2010;17:1734-1738.

7. Daiminger A, Bader U, Enders G. Pre- and periconceptional primary cytomegalovirus infection: risk of vertical transmission and congenital disease. Obstet Gynecol Surv 2005;60:420-422.

8. Turbadkar D, Mathur M, Rele M. Seroprevalence of torch infection in bad obstetric history. Indian J Med

9. Hosiba T, Asamoto A, YAbuki Y. Decreasing seropositivity of cytomegalovirus of pregnant women in Japan. Nihon Rinsho 1998;56:193-6.

10. Bate SL, Dollard SC, Cannon MJ. Cytomegalovirus seroprevalence in the United States: the national health and nutrition examination surveys, 1988-2004. Clin Infect Dis 2010;50:1439-1447.

11. Enders G, Bader U, Lindemann L, Schalasta G, Daiminger A. Prenatal diagnosis of congenital cytomegalovirus infection in 189 pregnancies with known outcome. Prenat Diag 2001;21:362-377.

\section{Citing this article}

Acharya D, Shrestha S, Bogati B, et al. Immune status in infection by cytomegalovirus in women with bad obstetric history. Int J Infect Microbial 2013;2(1);3-6. 